Most criticisms of arguments are (and must be) partly substantive, hence extra-logical. Take the use of counterexamples: Logic (in the broad sense of my book and this journal) dictates that a counter-example refutes a premise. Judith Thomson's violinist story is a counter-example to $\left(P 2^{\prime}\right)$ only if you have a right to unplug yourself from the violinist in the situation described. I think it is obvious that you do have such a right. But in saying so I make a substantive judgment-a moral one-that logic alone does not compel me to make.

Logic is like the law. To decide whether someone is guilty of a crime, legal principles must be combined with extra-legal judgments. The law limits the range of extralegal judgments that are relevant. It does not produce those judgments. To reconstruct and criticize an argument, logical principles must be combined with extralogical judgments that are relevant. It does not produce those judgments.

Maybe Fogelin merely wishes to charge me with not acknowledging this point, on which we agree. But I did acknowledge it, repeatedly. My stated purpose (see Preface) was to articulate the procedure typically used by philosophers for reconstructing and criticizing arguments. Although logically constrained, that procedure obviously depends heavily on extra-logical judgments. When discussing the reconstruction of arguments, I expressly and repeatedly call for judgments of the reasonableness of premises. I open Chapter 9 (p. 175) by pointing out at length that the evaluation of premises requires substantive knowledge and that the principles I present specify how to use such knowledge. I end my book with these words: "Logic alone is limited....Without topical knowledge or creativity, logic will never lead us anywhere. Without logic, however, topical knowledge and creativity will often lead us astray."

\section{5}

Although mistargeted, Fogelin's discussion brings out with force and clarity two questions that informal logicians ought to ponder:

1) If argument-criticisms are almost always partly logical and partly substantive, when can we say that an arguer has reasoned badly, as opposed to having made a substantive mistake? (Perhaps an error is one of reasoning rather than substance to the extent that the error is nonobvious, and so requires some effort at demonstration, even to those who accept all the critically relevant substantive judgments.)

2) How can teachers of informal logic avoid foisting (possibly controversial) substantive judgments on their students under the guise of teaching them how to reason better?
Note

This is a reply to the article by Robert Fogelin, "Charitable Reconstruction and Logical Neutrality", printed above. Fogelin refers to my book, The Art of Logical Reasoning (New York: Random House, 1981), and to a talk I gave at a conference at Carnegie-Melion University on Logic and Liberal Learning [reported in ILN, ii.1, pp. 9-13]. That talk now appears as a paper, "Logic as a LiberalArt," in Teaching Philosophy 4 (1981): 231-248. Page references in this reply are to The Art of Logical Reasoning.

Editors' Note: Professor Schwartz is in the Department of Government at the University of Texas, Austin.

\title{
Argumentum ad Hominem: Aut Bonum aut Malum?
}

\section{John Hoaglund Christopher Newport College}

\begin{abstract}
"To deliberately take the life of a human being is murder. It is surely repulsive from a moral stand point, and it is everywhere illegal, punishable by death or life imprisonment. Now the fetus is a human being. The science of genetics has proven conclusively that a unique human being is established by the 23 chromosome pairs constituted at conception. Why, as early as 3 to 4 weeks, a heartbeat is discernable, and at 8 weeks brain-wave activity can be monitored. So abortion has got to be unthinkable. Whoever deprives this fetus of life deliberately kills a defenseless human being, and that is murder."
\end{abstract}

Bob Dolan was talking to a group of friends. The topic arose in response to news reports of a proposed amendment to the U.S. Constitution (an amendment which Bob favored) enabling states to make abortion illegal despite the 1973 Supreme Court decision in Roe v. Wade. Sally Clark was not all all convinced. With more than a hint of excitement in her voice, she replied:

"Look, Bob, I'm sick of hearing men preach about the evils of abortion. And I do mean preach. Everyone knows you're a Catholic and that Catholics oppose abortion as a matter of religious faith. Fortunately we live in a nation that separates state and church, so that we don't have to have someone else's religious beliefs forced on us." 
A clearcut case of the circumstantial ad hominem fallacy, or perhaps most of us would agree. Bob's being a Roman Catholic is a circumstance about him as a person. Though it may be relevant to the issue in a broader context, it certainly doesn't loom as a factor in his argument. He doesn't argue: "Pope Paul VI affirms in his 1968 Enc iclical Humanae vitae ... etc.; so even therapeutic abortion is prohibited." $\mathrm{He}$ does argue by citing information about fetuses which he claims proves they are humans, and then contending that killing humans is wrong. Any attempt to meet this argument fairly would have to deal with whether his factual claims are accurate, whether they prove that fetuses are humans, and whether killing humans is always wrong. Sally doesn't really come to grips with these issues. Instead her rejoinder avoids them altogether. Since her ad hominem material is not directly relevant to Bob's argument, we say she commits the ad hominem fallacy.

Now l've just finished presenting the above subject to my 8:00 a.m. logic class, 25 or 26 students attending. The example serves its purpose well. Abortion is always controversial. Even some occasional snoozers are on edge, anticipating I'll now say something to offend them.

\section{I say, "Any questions?"}

Two, now three hands go up. With a bit more information I parry two students eager to delve further into the rights and wrongs of abortion.

Now the hand on the left, a third of the way back.

"Is it always a fallacy to base an argument on circumstances about a person? And if some of these arguments are good ones, how do we tell the good from the bad?"

Just the question we've been hoping for. I carry on.

Good question. There are some cases where circumstances about a person are the issue. For instance, when the subject is a certain person's qualifications to fill an important post. Here we can encounter a sound argument based on circumstantial ad hominem material. Look at this example, suggested by Alan Drury's 1959 novel, Advise and Consent.

The scene is a conference room of the U.S. Senate. The Foreign Relations Committee is meeting in closed session to examine the qualifications of Harold Powell, the President's nominee for the office of Secretary of State. Senator Sharp addresses the candidate.

"Mr. Powell, though I'm a family man myself, I don't have any objection to a 49-year-old bachelor becoming our next Secretary of State. There is a very delicate matter which, with reluctance, I must probe into. The importance of the post you are nominated to fill makes it imperative for me to do so. When confronted with our evidence, you admitted to this Committee-and I commend you for your frankness - that you are a homosexual. It may be that large numbers of Americans now accept homosexuality rather than merely tolerate it. But you don't seem to think so. Otherwise you would be an overt rather than a covert homosexual, and we would have less of a problem here. My fear is that some foreign power may uncover the same evidence turned up by our investigative staff, then use it to blackmail you and influence U.S. foreign policy in its favor. Can you say anything to allay this fear?"
"Senator, I'd like to point out respectifully that you are an unwitting victim of the ad hominem fallacy. You are directing attention to the man here, to circumstances in his private life. The real issue is how our nation's foreign policy is to be conducted, and whether it will be conducted effectively."

Is Senator Sharp guilty of the ad hominem fallacy? Not in any obvious way. The issue is whether this man is qualified to be Secretary of State. The information Sharp cites merits consideration because it bears significantly on the candidate's potential effectiveness as Secretary of State. Perhaps it should not be decisive, as the Senator seems to think. But a Committee that possessed this information yet failed to deal with it would certainly be remiss in its duty.

How do you tell in a given case whether an ad hominem argument is fallacious or not? These examples suggest one rule of thumb (there may be others). The ad hominem material tends to be fallacious when it directs attention ab re or away from the issue being considered. An ad hominem can be valid when the person or his circumstances are the issue, in which case it is ad rem. The individual participating in or witnessing the debate must decide, on the basis of his scrutiny of all the factors, whether the ad hominem material is pertinent to the issue or not. If there are degrees of relevance, then there may be degrees of fallaciousness also. To pounce on an opponent's argument as a blatant fallacy implies that there are fallacies that aren't blatant.

Of course no self-respecting logician will ever be satisfied with this account of the circumstantial ad hominem fallacy. There is no criterion sufficient to distinguish in all cases the illegitimate from the legitimate use of ad hominem material. That sense of neatness, or intellectual structure, or perhaps even elegance that we all admire in a clever decision procedure or an ingenious deduction is missing. Yet a case might still be made for continuing to teach the ad hominem in the introductory logic course, even against challenges as stiff as those noted recently by Anthony Blair (ILN, iv.1, 1981, p. 4).

A central contention of Maurice Finocchiaro in his able article $^{1}$ is that textbook accounts of fallacies are artificial. He thinks that people in real life never commit such fallacies, which exist only in their authors' minds (p 15). Obviously any example put in a textbook thereby becomes a textbook example, just as any example used in class thereby becomes a classroom example. If we want to get away from these informative tautologies, we must assume that some such examples can come from real life while others do not.

Do fallacies such as the ad hominem actually occur, and if so, how frequently? This can be an empirical question. Why not treat it as such? Suppose I am teaching English to foreign adults and one of my goals is a recognition vocabulary of the 4,000 to 5,000 most commonly used English words. If I want to know whether I should use and test a word like "aberration' I consult a list of word frequencies. 2 (Don't use it.)

I know what you're going to say: We can't handle our question that way because we have no studies of fallacy 
frequencies or argument frequencies. The reply is: Well, maybe we ought to have them. Perhaps some of the time of this generation's logicians would be well spent gathering such data, even on the basis of admittedly imperfect categorizations. Of course we could await a consensus on what is valid and what is fallacious in each case. But in the case of many fallacies we haven't achieved one since Aristotle's time. Is it over-optimistic to expect one by the year 2000? By this time a goodly number of students will have completed their education with no training in detecting and avoiding informal fallacies, and will probably be the worse off for it.

Karel Lambert and William Ulrich are among those who argue that until we have decision procedures it isn't useful to teach informal fallacies. 3 They exhibit their case with an example of the abusive ad hominem fallacy. Mr. Jenner has just advanced the claim that evidence $\mathbf{E}$ suggests President Nixon has obstructed justice. The committer of the fallacy rebuts the claim thus:

(P1) Jenner claims $E$ is strong evidence that Nixon is guilty of obstructing justice

(P2) But Jenner once advocated legalizing pot;

(P3) So E isn't strong evidence of Nixon's guilt.

Lambert and Ulrich urge that there is no point in identifying or teaching this as a fallacy because some other fallacious arguments have the same form but are not ad hominem fallacies, and yet other arguments have the same form and are not fallacies at all.

They analyze this argument as having the form A and B, therefore not $C$. Clearly their conclusions are not the only ones that can be inferred from this evidence. For instance, there may be something distinctive about the ad hominem fallacy which this simple argument scheme from propositional logic doesn't capture at all. The ad hominem fallacy, for example, is always directed at a person who has advanced a claim or thesis, yet their argument scheme reveals this not at all.

In one sense writers are contending that the ad hominem and other informal fallacies shouldn't be taught until they have been formalized to the point of having mechanical decision procedures. But surely one impulse for the spreading interest in informal logic is the realization that formalization, decision procedures, completeness proofs and the like tend to remove logic from the thinking tactics most people rely on when confronted with challenges. Teaching students to imitate computers may be fine for those whose students desire this and profit from it. The students from my introductory logic course tell me they benefit more from working with informal fallacies. Could one's stance on formalization be influenced by a conviction that the logical structure of the universe is known? Or that its discovery is imminent?

In another sense these writers are suggesting that accounts of informal fallacies are still capable of being improved. But isn't that precisely the goal of most of the good recent writing in this area? Is anyone claiming that all of the important questions have already been answered? I'm not sure they've even been asked.

Let me toss out a couple that intrigue me. In recent valuable analyses John Woods and Douglas Walton 4 tend to locate the fallaciousness of the ad hominem fallacy in inconsistency of one sort or another. Similarly Trudy Govier locates the fallaciousness of the tu quoque in the inconsistency of preaching and practice (ILN, iii.3, 1981, p. 2). Are all ad hominem fallacies inconsistent? is the ad hominem a fallacy because it is inconsistent? Or is the ad hominem a fallacy because it isn't ad rem-because it's to the man rather than to the point in those many cases where homo and res are different?

Sally's reply to Bob suggests irrelevance over inconsistency. Her claim, spelled out, is probably that rejecting abortion is an article of religious faith rather than rational persuasion for Bob as a Roman Catholic, so it is not binding on those who fail to share this religious faith. We convict her of the ad hominem fallacy for going to the man rather than coming to grips with his argument.

I've suggested that teaching the informal fallacies might not be completely futile even in cases where it is difficult or impossible to decide whether a given argument is fallacious. Let me illustrate with this variation on Sally's rejoinder to Bob.

"Look, Bob, science has established only that a fertilized ovum exists at conception. The question whether the fertilized ovum is a human in the sense of the homicide statutes is still an open one. Nor is it clear that all taking of human life is murder-self-defense and the enemy in wartime are obvious cases to the contrary. I'm really sick of hearing men preach about the evils of abortion. And 1 do mean men. Has it ever occurred to you that no man has ever suffered an unwanted pregnancy? A pregnancy resulting from rape and more loathed that a spreading lethal cancer? Haven't you ever notice how the strongest arguments in defense of abortion are made by women (e.g. Thompson), the strongest against by men (Noonan)?"

Does Sally commit the ad hominem fallacy here? Let your students work on this. If they're like some of mine, they expect you to sharpen their thinking skills. One way is to give them something worth thinking about, then refuse to do all of their thinking for them. When they get this one, let them go to work on Sally's first rejoinder citing Bob's religious faith, this time allowing her the same initial rebuttal of Bob's contentions as above. Maybe this will help make learning the argumentum ad hominem bonum magis quam malum.

\section{Footnotes}

1"Fallacies and the Evaluation of Reasoning," American Philosophical Quarterly, Vol. 18 (1981), p. 13-22.

2 Edward L. Thorndike and Irving Lorge, The Teacher's Word Book of 30,000 Words (New York, 1944).

3The Nature of Argument (New York, 1980), pp. 24-28.

4"Ad Hominem," Philosophical Forum, Vol. 8 (1977), pp. 1-20; Argument: The Logic of the Fallacies (Toronto, 1982), pp. 9-13. 